\title{
O design de enunciados e a resolução de problemas com o uso de tecnologias digitais na Educação Matemática de alunos com deficiência intelectual
}

\author{
Fabiane Fischer Figueiredo ${ }^{1}$
}

\section{RESUMO}

Nas aulas de Matemática, dos Anos Finais do Ensino Fundamental, o professor pode se deparar com alunos que possuem deficiência intelectual, o que lhe exigirá o (re)planejamento das práticas pedagógicas, de modo que proporcionem o seu desenvolvimento e aprendizagem. Entre as perspectivas metodológicas, que podem vir ao encontro dessa necessidade, está o Design de enunciados de problemas com o uso de tecnologias digitais em que são projetados, desenvolvidos e implementados os enunciados e esses avaliados para a proposta de resolução. Desse modo, apresentam-se os resultados de uma investigação realizada sob o paradigma qualitativo e como um estudo de caso, cujo objetivo geral foi investigar como os Designs de enunciados realizados pelo professor e a resolução dos problemas, por parte de uma aluna com deficiência intelectual, com o uso de tecnologias digitais contribui para que produza conhecimentos matemáticos, tecnológicos e acerca de temas de relevância social. Para atingi-lo, foi executado, em etapas, os Designs de quatro enunciados de problemas fechados e abertos, utilizando os documentos do Microsoft Office Excel e imagens de um site, que contextualizaram os problemas. Esses foram produzidos para serem propostos e resolvidos por uma aluna com deficiência intelectual, de um $6^{\circ}$ ano do Ensino Fundamental, e contribuíram para que aprendesse os conhecimentos matemáticos relativos à Contagem, Representação no Sistema Decimal e de Valores Monetários, em Tabelas, e Adição, Subtração e Multiplicação de Números Naturais, associandoos ao uso do computador e aos recursos do Excel e aos temas abordados, ligados às práticas do cotidiano.

Palavras-chave: Educação Matemática. Deficiência intelectual. Design de enunciados. Resolução de problemas. Tecnologias digitais. Anos Finais do Ensino Fundamental.

\section{Design of problem formulations and resolutions with the use of digital technologies in the Mathematics Education of students with intellectual disabilities}

\begin{abstract}
1 Pós-Doutora em Ensino de Ciências e Matemática (ULBRA), Doutora em Ensino de Ciências e Matemática (ULBRA), Mestra em Ensino de Matemática (UFN), Especialista em Educação Especial e Inclusiva (Dom Alberto) e Licenciada em Matemática (UNISC). Professora da Escola Estadual de Ensino Médio João Habekost, Rio Pardo, Rio Grande do Sul, Brasil. Orcid iD: https://orcid.org/0000-0003-1236-0890. E-mail: fabianefischerfigueiredo@gmail.com
\end{abstract}


In Mathematics classes, the teacher may have students with intellectual disabilities. This situation will require from him or her a commitment to (re)plan pedagogical practices to promote their development and learning. Among the methodological perspectives which may meet this need is the design problem formulations with the use of digital technologies, in which the formulations are designed, developed, implemented, and subsequently evaluated as for the proposed resolutions. In this paper, the results of a qualitative case study are presented. The aim of the investigation was to understand how designs of mathematical problem formulations made by the teacher, and the resolution of problems by a student with intellectual disability, with the use of digital technologies, contribute to the production of mathematical, technological and socially relevant knowledge. To achieve this goal, the designs of four closed and open problem formulations were carried out in stages, using Microsoft Office Excel documents and images from a website, which contextualized the problems. These were produced to be proposed and solved by a 6th-grade student with intellectual disability, and they aided her to learn the mathematical knowledge related to counting, representation in the decimal and monetary values systems, in tables, and addition, subtraction and multiplication of natural numbers, associating them to the use of computers and Excel resources and to the topics covered, linked to everyday practices.

Keywords: Mathematics Education. Intellectual disability. Design of formulations. Problem solving. Digital Technologies. Final Years of Elementary School.

\section{El diseño de ponentes y la solución de problemas con el uso de tecnologías digitales en la Educación Matemática de estudiantes con discapacidad intelectual}

\section{RESUMEN}

En los años finales de la educación primaria de las clases de Matemáticas, el docente puede encontrarse con alumnos con discapacidad intelectual, lo que le exigirá (re)planificar las prácticas pedagógicas, con la intención de facilitar el desarrollo y aprendizaje. Entre las perspectivas metodológicas, que pueden cubrir esta necesidad, se encuentra el Design de enunciados de problemas con la ayuda de tecnologías digitales, en los que se diseñan, desarrollan e implementan los enunciados para resolver la propuesta. Presentamos los resultados de una investigación, realizada bajo el paradigma cualitativo y con um estudio de caso, cuyo objetivo general fue indagar cómo los Diseños de enunciados realizados por el docente y la resolución de problemas por parte de un alumno con discapacidad intelectual, con la ayuda de tecnologías digitales, contribuye a la producción de conocimiento matemático y tecnológico y sobre temas de relevancia social. Para lograr este objetivo, hemos ejecutado varias etapas, el Design de cuatro enunciados de problemas cerrados y abiertos se ejecutaron utilizando documentos de Microsoft Office Excel e imágenes de un sitio web, que contextualizaron los problemas. Estos fueron producidos para ser propuestos y resueltos por un alumno con discapacidad intelectual, de $6^{\circ}$ año de primaria, y contribuyeron para el aprendizaje de los conocimientos matemáticos relacionados con el Conteo, Representación en el Sistema de Valores Decimales y Monetarios, en Tablas y Suma, Resta y Multiplicación de Números Naturales, asociándolos al uso de computadores y recursos de Excel y a los temas tratados, vinculados a las prácticas cotidianas. 
Palabras clave: Educación Matemática. Discapacidad intelectual; Diseño de la declaración. Solución de problemas. Tecnologías digitales. Años Finales de la escuela primaria.

\section{Introdução}

A Educação, com a finalidade de promover a Inclusão de alunos com deficiência intelectual no ensino regular vem sendo alvo de estudos e discussões, tanto nacional como internacionalmente pelos governos, associações e organizações que apoiam tais pessoas, pesquisadores e profissionais da Educação e Saúde. Em se tratando da Educação Matemática, nos Anos Finais do Ensino Fundamental, o planejamento pedagógico deve passar por adequações, em que perspectivas metodológicas e recursos sejam escolhidos e utilizados, de forma que os interesses, o nível de desenvolvimento e os conhecimentos prévios desses alunos possam ser valorizados, no processo de ensino e aprendizagem.

Por isso, entende-se que a perspectiva metodológica do Design de enunciados e a resolução de problemas com o uso de tecnologias digitais, pode contribuir para que os alunos com deficiência intelectual aprendam novos conhecimentos matemáticos, articulando-os aos tecnológicos e à abordagem de temas de relevância social, conforme as necessidades pessoais e educacionais (FIGUEIREDO, 2017, 2019). O Design é realizado pelo professor, que deve executá-lo em etapas que utilizam as tecnologias digitais, com o propósito de obter os enunciados dos problemas, de modo que possam ser propostos e resolvidos com o uso de tais recursos.

Devido à necessidade de constante (re)planejamento das práticas pedagógicas no ensino da Matemática, para que sejam atendidas as necessidades pessoais e educacionais dos alunos com deficiência intelectual, no $6^{\circ}$ ano, dos Anos Finais do Ensino Fundamental, surgiu a necessidade de realizar esta investigação, para apontar como uma perspectiva metodológica, o Design de um ou mais enunciados realizado pelo professor e a resolução de problemas com o uso de tecnologias digitais, por parte de tais alunos que apresentam dificuldades na interpretação e resolução, ao empregarem os conhecimentos matemáticos que a eles 
foram ensinados no ambiente escolar (nos Anos Iniciais e no próprio $6^{\circ}$ ano do Ensino Fundamental) ou fora dele, assim como utilizando as tecnologias digitais e compreendendo os temas abordados, quando esses são relevantes socialmente. Nesse intuito, delimitou-se à questão diretriz: Como ocorre a resolução de problemas com uso de tecnologias digitais, por parte de uma aluna com deficiência intelectual, do $6^{\circ}$ ano, quando os Designs dos enunciados são realizados com tais recursos pelo professor de Matemática, a fim de ocorra a produção de conhecimentos matemáticos, tecnológicos e acerca de temas de relevância social?

Com a realização da investigação, buscou-se afirmar a necessidade de que os enunciados de problemas, em que as tecnologias digitais são utilizadas, sejam produzidos pelo próprio professor de Matemática, do(s) aluno(s) com deficiência intelectual do $6^{\circ}$ ano, pois acompanha 0 seu desempenho em sala de aula. Tais problemas, sendo fechados ou abertos, os permitem fazer explorações e empregar a linguagem oral, escrita e matemática nos processos de resoluções, que incidam no aprimoramento e/ou na aprendizagem de conhecimentos matemáticos, correlacionando-os aos tecnológicos e ao estudo dos temas de relevância social abordados. Para tanto, delimitou-se o objetivo geral: investigar como os Designs de enunciados realizados pelo professor e a resolução dos problemas, por parte de uma aluna com deficiência intelectual, com o uso de tecnologias digitais, contribui para que produza conhecimentos matemáticos, tecnológicos e acerca de temas de relevância social.

A investigação veio ao encontro das orientações mencionadas nos documentos oficiais, nacionais e internacionais e de pesquisas realizadas na área da Educação Especial e Inclusiva e da Educação Matemática, nos Anos Finais do Ensino Fundamental, pois foi conduzida sob o paradigma metodológico qualitativo, em que utilizou-se o método estudo de caso, em virtude que a pesquisadora e professora de Matemática realizou os Designs de enunciados de problemas com o uso de tecnologias digitais, para propôlos e serem resolvidos por uma aluna com deficiência intelectual, de um $6^{\circ}$ ano do Ensino Fundamental na qual lecionava. Sendo assim, apresentam-se, 
na sequência, o referencial teórico elaborado, os procedimentos metodológicos adotados, os resultados obtidos e as respectivas análises, bem como as conclusões construídas.

\section{Referencial teórico}

No Brasil, principalmente, a partir da "Constituição da República Federativa do Brasil" (BRASIL, 1988) e da "Declaração de Salamanca" (ESPANHA, 1994), que foram efetivadas as publicações de documentos oficiais, quem fazem destaque à Educação Especial e Inclusiva. Com base, nessas orientações, são buscadas alternativas que, também, possibilitem a Educação Matemática, como o uso de perspectivas metodológicas e recursos, que atendam às necessidades pessoais e educacionais dos alunos com deficiência intelectual.

A "Constituição da República Federativa do Brasil de 1988", no Título VIII "Da Ordem Social", Capítulo III "Da Educação, da Cultura e do Desporto" e Seção I "Da Educação", ressalta, nos Artigos 205 e 206, que a Educação é um direito de todos e dever do Estado e da família, com a colaboração da sociedade, que devem promover o desenvolvimento da pessoa portadora de necessidades especiais, de modo que ocorra o exercício da cidadania e a preparação para o trabalho, com igualdade de condições. No Artigo 208 e Inciso III, é salientado que o Estado deve garantir o "atendimento educacional especializado aos portadores de deficiência, preferencialmente na rede regular de ensino" (BRASIL, 1988, p. 124).

A "Declaração de Salamanca", que foi elaborada na Conferência Mundial de Educação Especial, ocorrida entre 7 e 10 de junho de 1994, em Salamanca-ES, contribuiu para a elaboração de diretrizes, que reafirmaram o compromisso de inserção de crianças, jovens e adultos, com necessidades especiais, no sistema regular de ensino e das ações que são esperadas dos governos e organizações (ESPANHA, 1994). Nesse documento, é afirmado que a Educação Inclusiva exige mudanças, nos aspectos de escolarização (currículo, prédios, organização escolar, pedagogia, avaliação, profissionais, 
filosofia da escola e atividades extracurriculares), em vista da efetivação de uma forte pedagogia, que ofereça as oportunidades curriculares, que estejam relacionadas às experiências dos alunos e que os motivem e valorizem as suas habilidades e interesses.

Com base em tais documentos, outros foram publicados, que regulamentaram e expuseram sugestões, como podem ser observados no Quadro 1.

QUADRO 1 - Principais orientações dos documentos oficiais para a Educação Especial e Inclusiva

\begin{tabular}{|c|c|}
\hline DOCUMENTO & PRINCIPAIS ORIENTAÇŌES PARA A EDUCAÇÃO ESPECIAL E INCLUSIVA \\
\hline $\begin{array}{l}\text { Leis de Diretrizes e } \\
\text { Bases da Educação } \\
\text { Nacional (LDB) } \\
\left.\text { (lei } n^{\circ} 9.394 / 1996\right)\end{array}$ & $\begin{array}{l}\text { No Capítulo V "Da Educação Especial" e no Artigo 59, são destacados } \\
\text { que os sistemas de ensino deverão assegurar os currículos, os métodos, } \\
\text { as técnicas, os recursos educativos e a organização específicas, entre } \\
\text { outras orientações (BRASIL, 2017). }\end{array}$ \\
\hline $\begin{array}{l}\text { Diretrizes nacionais } \\
\text { para a educação } \\
\text { especial na educação } \\
\text { básica (2001) }\end{array}$ & $\begin{array}{l}\text { Na seção 7, intitulada "Curículo", são mencionados que esse deve ser } \\
\text { revisado e adequado, abrangendo graduais e progressivas adaptações, } \\
\text { de acordo com as dificuldades de aprendizagem, em que os conteúdos } \\
\text { são permeados pelos "[...] métodos e técnicas, recursos educativos e } \\
\text { organizações específicas da prática pedagógica [...]" (BRASIL, 2001, } \\
\text { p. 57). }\end{array}$ \\
\hline $\begin{array}{l}\text { Lei Brasileira de } \\
\text { Inclusão da Pessoa } \\
\text { com Deficiência } \\
\text { (Estatuto da Pessoa } \\
\text { com Deficiência) } \\
\left.\text { (lei } n^{\circ} 13.146\right)\end{array}$ & $\begin{array}{l}\text { No Capítulo IV "Do Direito à Educação" e no Artigo 27, são frisados que } \\
\text { a Educação envolve o desenvolvimento dos talentos e habilidades, } \\
\text { sendo essas físicas, sensoriais, intelectuais e sociais, e as características, } \\
\text { os interesses e as necessidades de aprendizagem (BRASIL, 2015). }\end{array}$ \\
\hline $\begin{array}{c}\text { Base Nacional Comum } \\
\text { Curricular (BNCC) } \\
\text { (2018) }\end{array}$ & $\begin{array}{l}\text { Na Base, é feita a menção, na Seção "O pacto interfederativo e a } \\
\text { implementação da BNCC" e na Subseção "Base Nacional Comum } \\
\text { Curicular: igualdade, diversidade e equidade", que o planejamento } \\
\text { pedagógico deve ter como foco a equidade e "[...] o compromisso com } \\
\text { os alunos com deficiência, reconhecendo a necessidade de práticas } \\
\text { pedagógicas inclusivas e de diferenciação curricular [...]" (BRASIL, 2018, } \\
\text { p. 16). }\end{array}$ \\
\hline $\begin{array}{l}\text { Referencial Curricular } \\
\text { Gaúcho, para o Ensino } \\
\text { Fundamental (2018) }\end{array}$ & $\begin{array}{l}\text { No Capítulo } 2 \text { "Modalidades de Ensino" e na Seção 2.1, a Educação } \\
\text { Especial é considerada uma modalidade que perpassa os níveis, etapas } \\
\text { e demais modalidades de ensino, e pode ser apoiada pelo Atendimento } \\
\text { Educacional Especializado (AEE), em Salas de Recursos Multifuncionais. } \\
\text { Para que a Educação Inclusiva ocorra, "deve ser considerado tanto o } \\
\text { conhecimento prévio e o nível atual de desenvolvimento do estudante, } \\
\text { quanto às possibilidades de aprendizagem futura, configurando uma } \\
\text { ação pedagógica processual e formativa que analisa o desempenho do } \\
\text { estudante em relação ao seu progresso individual, prevalecendo na } \\
\text { avaliação os aspectos qualitativos que indiquem as intervenções } \\
\text { pedagógicas do professor" (RIO GRANDE DO SUL, 2018, p. 36). }\end{array}$ \\
\hline
\end{tabular}

Fonte: Brasil $(2001,2015,2017,2018)$ e Rio Grande do Sul (2018).

Os documentos indicam os direitos, as orientações gerais e as políticas públicas, que podem proporcionar à Educação Especial e Inclusiva, como as ações do Poder Público e aquelas que são esperadas das escolas e profissionais da Educação. Segundo esses, as escolas de ensino regular 
necessitam proporcionar meios que permitam as relações de respeito, a dignidade humana, a busca de identidade e a igualdade de direitos e as oportunidades educacionais para todos os alunos, que proporcionem a aprendizagem e democratização do ensino, Inclusão social e cidadania (BRASIL, 2001, 2015, 2017, 2018; RIO GRANDE DO SUL, 2018). Os alunos com necessidades especiais deverão estar inseridos em classes de ensino regular e terem o Atendimento Educacional Especializado (AEE), em Salas de Recursos Multifuncionais, com professores especializados.

Entre as necessidades especiais, que os alunos podem apresentar, destaca-se a deficiência intelectual, cujo termo foi adotado recentemente, nas áreas clínica e acadêmica e pelas políticas públicas e educacionais, já que a sua denominação, segundo a Associação Americana de Deficiências Intelectuais e do Desenvolvimento (AAIDD), era comumente conhecida como retardo mental (USA, 2019). Ela se manifesta no período de desenvolvimento, antes dos 18 anos, e caracteriza-se por limitações no Funcionamento Intelectual e Comportamento Adaptativo, expressas pelas habilidades conceituais, sociais e práticas cotidianas (USA, 2019; SCHALOCK et al., 2018).

Por isso, conforme Gomes et al. (2007), os alunos com deficiência intelectual devem ser avaliados durante 0 ano letivo, para que sejam conhecidos os seus avanços, no entendimento dos conteúdos curriculares. Os autores (2007, p. 17), ressaltam que as práticas escolares precisam ser recriadas, para que ocorra a proposta de atividades diversas para um mesmo conteúdo e os alunos possam escolher as que desejarem realizar, assim como devem ser "[...] reconhecidos e valorizados os conhecimentos que é capaz de produzir, segundo suas possibilidades [...]".

No que se refere à Educação Matemática, Miranda e Pinheiro (2016), apontam, segundo a teoria vygotskyana, que os alunos com deficiência intelectual precisam ter oportunidades de construir os conceitos matemáticos, por meio de situações de caráter social e que sejam significativas na vida cotidiana. No que concerne à resolução de problemas ou às situações-problemas, na perspectiva de trabalho interdisciplinar e 
contextualizado, as autoras (2016, p. 705) afirmam que, tal aluno, pode elaborar "[...] suas funções psíquicas superiores baseadas em situações que se tornam significativas para ele", se esforçando para pensar nas estratégias, caso esteja motivado e as suas necessidades forem consideradas.

Conforme Seibert e Groenwald (2014), os alunos com Necessidades Educativas Especiais Intelectivas (NEEI), em salas de aulas regulares, exigem do professor de Matemática a compreensão das suas distintas maneiras pessoais de aprendizagem, por causa das necessidades de desenvolvimento e compreensão dos conceitos de: Número, Sistema de Numeração Decimal, Operações no Conjunto dos Números Naturais, Sistema Monetário, entre outros. Em relação às possibilidades de intervenção pedagógica cognitiva, sugerem o uso das Tecnologias de Informação e Comunicação (TIC), para propor e resolver problemas, uma vez que favorecem o ambiente motivador, em que a criação e aplicação de estratégias possibilitem, aos poucos, deixar de lado o uso do material concreto e a contagem nos dedos e passe a usar os algoritmos, fazer os cálculos mentais e abstrair conhecimentos.

Desse modo, entende-se que, entre as perspectivas metodológicas, que podem favorecer a Educação Matemática de alunos com deficiência intelectual, está o Design e a resolução de problemas com o uso de tecnologias digitais. Segundo Figueiredo $(2017,2019)$, o Design de problemas com o uso de tecnologias digitais consiste na produção de enunciados, de acordo com os objetivos pretendidos no ensino da Matemática, do uso de tecnologias digitais e do estudo, da discussão e reflexão acerca de temas de relevância social, para que sejam propostos e resolvidos, também, com o uso desses recursos.

No Design, o(s) professor(es), no papel de designer(s), podem considerar os interesses, os conhecimentos prévios e o nível de desenvolvimento cognitivo dos alunos e as condições de infraestrutura do ambiente escolar, para que, através da resolução dos problemas, sejam aprimorados e/ou aprendidos conhecimentos matemáticos, tecnológicos e de caráter social (FIGUEIREDO, 2017, 2019). Além disso, são criados meios para que competências e habilidades sejam desenvolvidas (tomada de 
decisões, reflexão, elaboração de estratégias, entre outras) e aspectos atribuídos (exploração, visualização, experimentação, produção escrita, comunicação, simulação, entre outros), que, com o uso de tecnologias digitais, podem ser potencializados.

Ademais, podem ser produzidos enunciados de problemas fechados ou abertos. Entretanto, a escolha por um determinado tipo depende, tal como preconiza Allevato (2008), dos objetivos delimitados pelo(s) professor(es): nos fechados, o processo de resolução costuma ser pré e univocamente determinado; e, nos abertos, existe a exploração de conteúdos e a valorização de ideias e escolhas do resolvedor. Ainda, sobre os tipos de problemas, Souza e Santos $(2007$, p. 7) salientam que, nos fechados, são aplicados um ou mais algoritmos e encontrada a operação mais adequada, para ser executada sem erro; e, nos abertos, o processo de resolução é um meio para a elaboração de estratégias, o desenvolvimento de habilidades (tentar, supor, testar e provar) e a produção de conhecimento.

Tal Design pode ser executado em etapas, como as que são propostas por Filatro (2008), para a produção de Designs de Sistemas Instrucionais: análise da necessidade, projeto, desenvolvimento e implementação da solução e avaliação da mesma. Para auxiliar o processo, podem ser usados os recursos de apoio, entre eles: os relatórios, os roteiros e o storyboard ${ }^{2}$.

A resolução desses problemas com o uso de tecnologias digitais pode vir ao encontro do que enfatiza Pais (2013), que um dos seus objetivos de tal atividade é desenvolver intelectualmente os alunos, no que diz respeito à ampliação do significado dos conceitos e ao desenvolvimento de aspectos teóricos na Educação Matemática, interligando-os a outros conhecimentos, que são trabalhados nas demais disciplinas e/ou que se apresentam em situações do cotidiano. Ao terem oportunidade de resolver problemas,

\footnotetext{
2 É um recurso utilizado "[...] na fase de pré-produção, [...] [que] funciona como uma série de esquetes (cenas) e anotações que mostram visualmente como a seqüência (sic) de ações deve se desenrolar" (FILATRO, 2008, p. 60).
} 
podem aprender conceitos matemáticos e desenvolver as competências: criatividade, comunicação de ideias, entre outras.

\section{Procedimentos metodológicos}

Para realizar a investigação de modo que atingisse o objetivo geral de investigar como os Designs de enunciados realizados pelo professor e a resolução dos problemas, por parte de uma aluna com deficiência intelectual, com o uso de tecnologias digitais, contribui para que produza conhecimentos matemáticos, tecnológicos e acerca de temas de relevância social, bem como os objetivos específicos de investigar como o Design de enunciados de problemas com o uso de tecnologias digitais pode vir ao encontro das necessidades pessoais e educacionais de uma aluna com deficiência intelectual; e investigar como o processo de resolução de problemas fechados e abertos, que abordam temas de relevância social e com 0 uso de tecnologias digitais, possibilitam a aprendizagem de conhecimentos matemáticos, adotou-se o paradigma metodológico qualitativo, por se tratar de uma pesquisa educacional. Esteban (2010), declara que, tal paradigma, necessita de uma relação com os métodos, a fundamentação epistemológica e o enfoque teórico, visto que, por ser uma atividade sistemática, pode orientar a compreensão de fenômenos educativos e sociais, a transformação das práticas e cenários socioeducativos, a tomada de decisões e o descobrimento e desenvolvimento organizado de conhecimentos.

Como método, escolheu-se o estudo de caso, pois, conforme a autora (2010, p. 183), esse possibilita "a identificação, seleção, contextualização e justificativa do caso ou casos a abordar [...]". Nesse viés, com a finalidade de obter os dados, a pesquisadora e professora de Matemática realizou, no segundo semestre de 2019, os Designs de quatro enunciados de problemas utilizando as tecnologias digitais, para propô-los a uma aluna com 
deficiência intelectual leve ${ }^{3}$, do $6^{\circ}$ ano do Ensino Fundamental, de uma Escola Estadual, localizada na zona rural, do município de Rio Pardo-RS-BR.

Os Designs dos enunciados foram realizados de acordo com as necessidades pessoais e educacionais de tal aluna, mediante a verificação dos registros das observações da professora do AEE, da Sala de Recursos Multifuncionais da Escola, e da pesquisadora e sua professora de Matemática. Os enunciados abordaram os temas "Alunos que constituem uma turma" e "Situações vividas em uma Loja" (dois enunciados para cada, um fechado e outro aberto) e foram produzidos em dois documentos do Excel, que apresentaram imagens do site Depositphotos.com (<www.depositphotos.com>) e eram consoantes os mesmos.

A aluna os resolveu em três horas-aulas, no turno oposto de suas aulas regulares, sendo orientada, na ocasião, pela pesquisadora e sua professora de Matemática. Os instrumentos utilizados na coleta de dados foram: as observações participantes, feitas pela pesquisadora e professora e registradas, por escrito, em um documento de Word; e, os registros escritos da pesquisadora e professora, feitos em storyboards, produzidos em documentos de Excel e Word, onde explicitou os processos e as informações que auxiliaram os Designs e resultaram nos enunciados, bem como da aluna, realizados nos mesmos documentos de Excel, em que são apresentados os enunciados, e em folhas de ofício, onde realizou algumas das contagens e a maioria dos cálculos na resolução.

Os dados coletados foram analisados mediante o uso do referencial teórico, os objetivos geral e específicos e o problema de investigação, considerando as características dos estudos qualitativos: o contexto, em que se deu os Designs dos enunciados, os resultados desses e a resolução dos problemas; o caráter interpretativo, em buscou-se justificar, elaborar e integrar os aportes teóricos aos resultados; e, reflexibilidade, em que foi dada

3 É uma das classificações clínicas ou faixas psicométricas, em que o Quociente de Inteligência (QI) está entre 50 e 69 e apresenta como características: o desenvolvimento mais lento e atrasado, no início da vida, e a capacidade limitada em usar os conceitos abstratos, de analisar e sintetizar (KE; LIU, 2015). 
a atenção às observações e compreensões da pesquisadora e professora, e aos registros escritos da aluna, tal como menciona Esteban (2010).

\section{Resultados da investigação}

No primeiro momento, como parte do planejamento pedagógico da pesquisadora e professora de Matemática, foram realizados, em etapas, os Designs dos quatros enunciados dos problemas, utilizando as tecnologias digitais, e, em cada uma delas, ocorreram ações, que foram planejadas e registradas em storyboards. Posteriormente e no segundo momento, houve a proposta de resolução dos problemas, a aluna com deficiência intelectual escolhida.

De acordo com as etapas de um Design de Sistemas Instrucionais (FILATRO, 2008), realizou-se os Designs dos quatro enunciados. Na etapa inicial análise da necessidade, foi escolhida uma aluna com deficiência intelectual, pois, mediante a análise dos registros das observações da professora do AEE, da Sala de Recursos Multifuncionais da Escola, e da pesquisadora e professora de Matemática da mesma, essa apresentava interesse e dedicação, mas precisava de um tempo maior para a realização das atividades. Também, demonstrava certa dificuldade na interpretação de problemas, na elaboração de estratégias e no uso de conhecimentos prévios na resolução de problemas contextualizados, que abordavam temas de relevância social e que envolviam as Quatro Operações com os Números Naturais, mesmo em se tratando de problemas de nível fácil e adaptados, bem como na escrita de soluções. Esses registros permitiram (re)pensar e (re)criar a prática docente (GOMES et al., 2007), pois auxiliaram na identificação de suas principais dificuldades e incidiram na decisão de realizar os Designs dos enunciados, de forma que os problemas podessem minimizá-las (FIGUEIREDO, 2017, 2019).

$\mathrm{Na}$ segunda etapa, denominada projeto, desenvolvimento e implementação, ocorreram as escolhas: dos temas "Alunos que constituem uma turma" e "Situações vividas em uma Loja", que se aproximavam, em parte, de suas vivências no cotidiano; das tecnologias digitais que seriam 
utilizadas nos Designs, no caso os recursos do Microsoft Office Excel, para o preenchimento de lacunas em Tabelas ou frases, para mostrar as explicações, de forma detalhada, com o uso do recurso "Comentário", e os feedbacks, por meio de mensagens que avisariam se as respostas digitadas estavam ou não corretas, e da Internet, para a pesquisa de imagens, no Depositphotos.com, que viessem ao encontro dos temas e das informações que seriam escritas nos enunciados; e dos conhecimentos matemáticos que seriam trabalhados, como a Contagem, Representação no Sistema Decimal e de Valores Monetários, Adição com e sem transporte, Subtração com e sem retorno e Multiplicação de Números Naturais, e Representação de informações e dados numéricos em Tabelas. Essas escolhas são, na verdade, resultantes da compreensão pedagógica da pesquisadora e professora de Matemática, quanto às necessidades da aluna e à forma pessoal que essa poderia aprender e compreender tais conceitos (PAIS, 2013; SEIBERT; GROENWALD, 2014).

$\mathrm{Na}$ terceira e última etapa, intitulada avaliação dos enunciados, houve a verificação das respostas, se eram as adequadas e forneciam os feedbacks correspondentes, bem como o aprimoramento das frases e dos aspectos estéticos (cores, tamanho de fontes, linhas e colunas das Tabelas). Ademais, ocorreu a proposta de resolução dos problemas à aluna escolhida.

Para resolvê-los, a aluna e a pesquisadora e professora se reuniram em uma sala, no turno oposto das aulas de Matemática do $6^{\circ}$ ano. A princípio, utilizariam apenas os recursos: lápis, borracha, folhas de ofício e computadores (um para cada), com os enunciados disponibilizados.

Os enunciados referentes ao tema "Alunos que constituem uma turma", receberam o título "Total de alunos" e foram nomeados como Situação 1 e 2 (Figura 1). Eles possuem frases com comentários, que podem auxiliar o processo de resolução e a escrita das soluções. 
FIGURA 1 - Situação 1 e 2 do "Total de alunos"

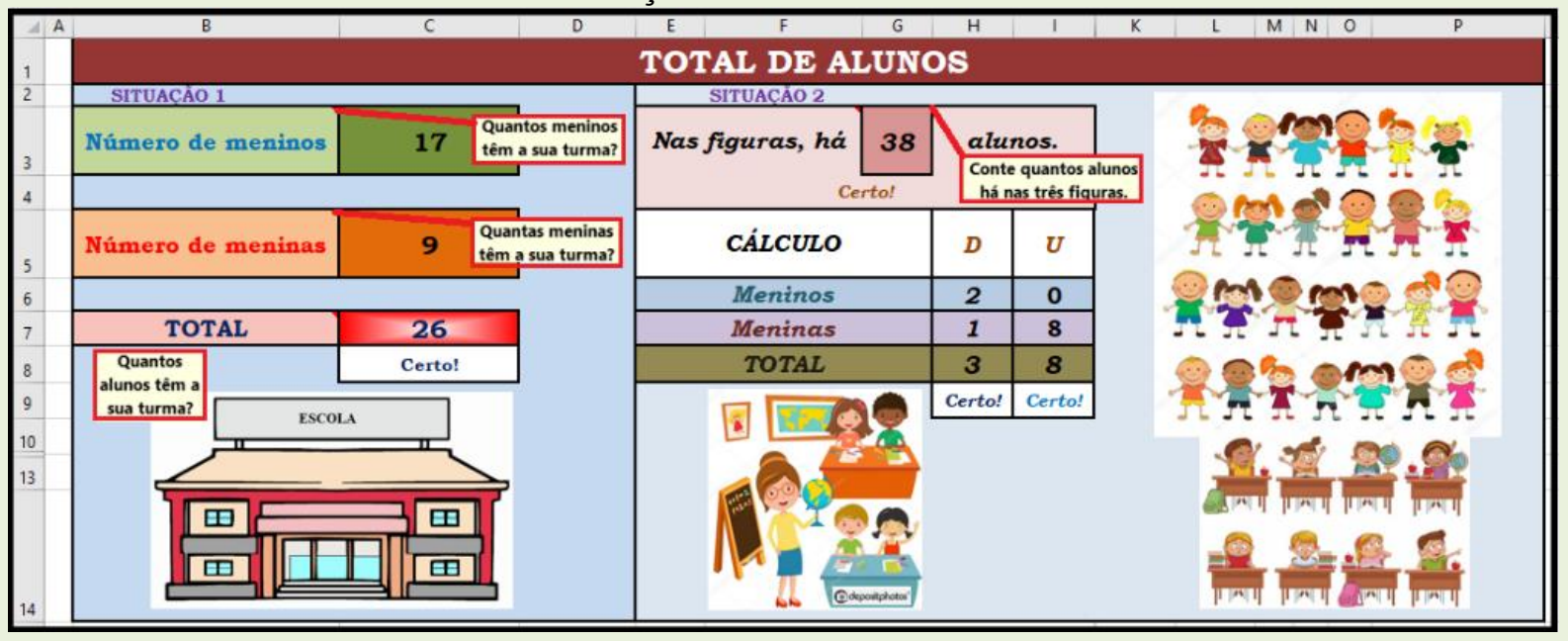

Fonte: a pesquisa.

Na Situação 1, em que o objetivo era a contagem da quantidade de meninos e meninas que haviam em sua turma e somá-las, tem-se um problema do tipo aberto, visto que existem três opções de preenchimento de lacunas, que possibilitam a escrita de quaisquer valores e as ideias pessoais da aluna poderiam ser valorizadas (ALLEVATO, 2008).

No processo de resolução, a aluna tomou a decisão de fazer a contagem de seus colegas, utilizando os dedos e observando o gênero, porém, na medida em que a quantidade aumentou, confundiu-se e precisou iniciá-la novamente. Diante de tal dificuldade, foi preciso fornecer uma lista com os nomes de seus colegas (outro recurso utilizado), para que a auxiliasse na contagem e encontrasse a solução correta. Inclusive, decidiu excluir dois colegas, que não estavam mais estudando na Escola, cuja decisão tornou a resposta correta.

Em seguida, para obter o valor total de alunos, realizou o cálculo de Adição em uma folha de ofício, utilizando os valores que contou, e obteve o valor correto. Ao registrá-los nas lacunas, apresentou dificuldades em fazer o uso das teclas de computador, precisando, assim, ser auxiliada, para que pudesse reconhecer quais eram necessárias na digitação.

$\mathrm{Na}$ Situação 2, que é um problema do tipo fechado, com o preenchimento de lacunas, em uma frase e numa Tabela, e a resolução seria pré determinada (ALLEVATO, 2008), a finalidade era que identificasse os 
desenhos que representavam os meninos e as meninas nas três imagens e determinasse o total (somando os valores dos dois gêneros), representando os algarismos, ao digitá-los, nas casas decimais correspondentes.

Na sua resolução, a aluna iniciou a contagem oralmente e utilizando os alunos expostos nas imagens. A obtenção do total foi de nível fácil, uma vez que digitou a quantidade, de forma correta, na lacuna da frase. No entanto, ao fazer a contagem por gênero, necessitou iniciar a contagem, diversas vezes.

Diante disso, a pesquisadora e professora fez questionamentos e a orientou que traçasse duas colunas na folha e anotasse a quantidade por gênero, conforme o que havia identificado em cada uma das filas, nas imagens. Na primeira tentativa, sem o seu auxílio, esqueceu de contar alguns, mas o erro foi por ela constatado, quando precisou realizar a soma de meninos e meninas na folha e comparou com o resultado que havia escrito na lacuna da frase. Então, precisou de ajuda novamente, para contar o número de meninos por fila e registrar a quantidade que havia em cada, parcialmente; o mesmo se deu na determinação do número de meninas. Ao final, fez a soma das quantidades e verificou se estava correta, pelo feedback dado pelo enunciado. O recorte desses registros pode ser observado na Figura 2.

FIGURA 2 - Registros da aluna ao resolver a Situação 2
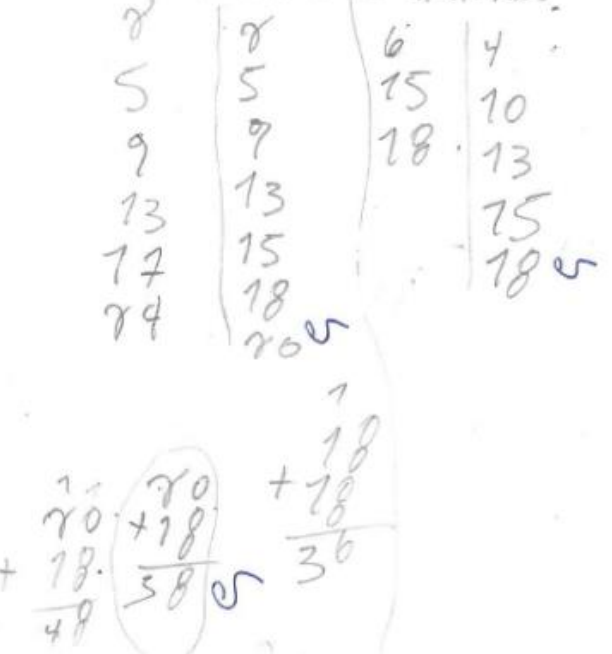

Fonte: a pesquisa. 
Ao registrar os resultados, na Tabela, demonstrou dificuldades em digitar os algarismos nas casas correspondentes (dezena e unidade), necessitando, desse modo, de explicações. Quanto ao uso das teclas do computador e a escrita nas lacunas, teve certa facilidade, já que usou as mesmas que foram ensinadas e aprendidas na Situação 1 .

Os enunciados do tema "Situações vividas em uma Loja", foram intitulados "Loja" e em Situação 3 e 4, respectivamente (Figura 3). Na Situação 3, existem três frases de comentários e, na Situação 4, há um questionamento, que pode instigar a resolução.

FIGURA 3 - Situação 3 e 4 da "Loja"

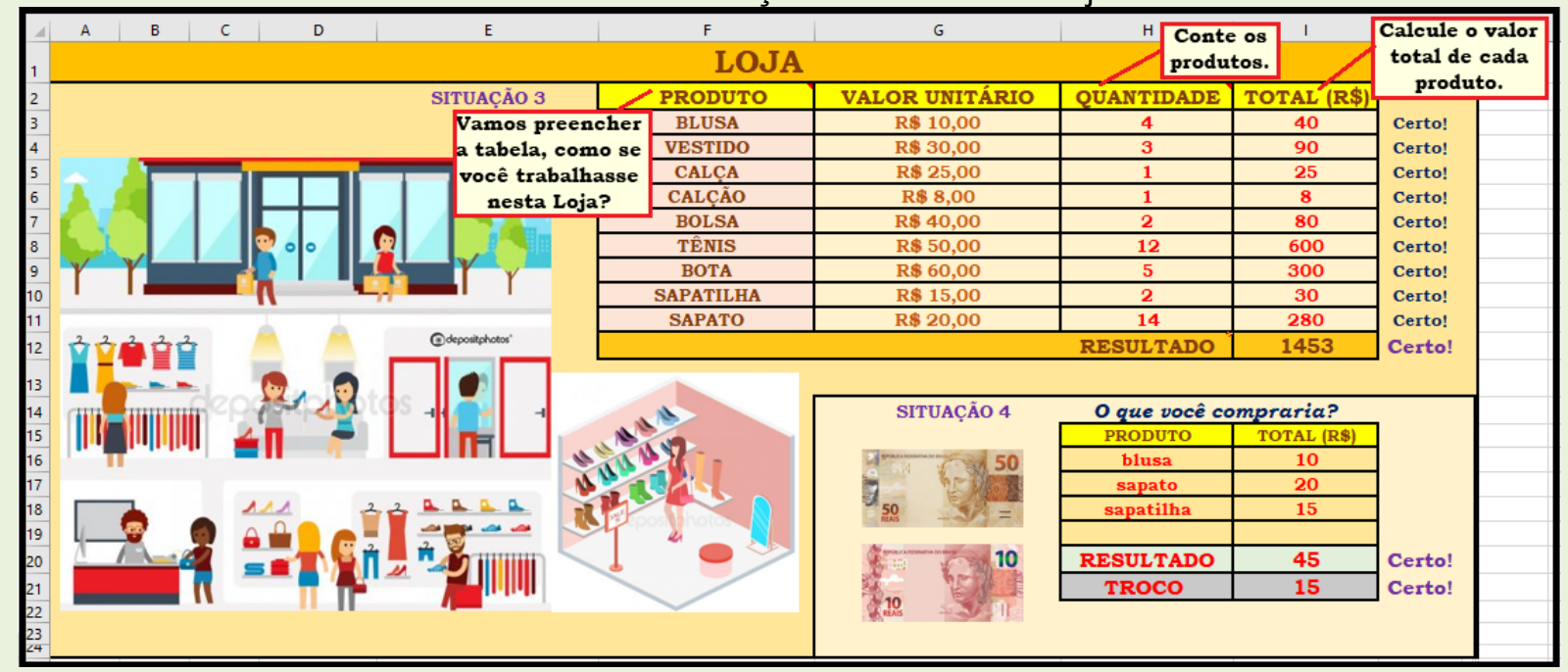

Fonte: a pesquisa.

Na Situação 3, o propósito era que preenchesse as colunas da Tabela: "Quantidade", verificando a quantidade de produtos que haviam nas duas imagens; e "Total(R\$)", com o valor correspondente a cada quantidade de produtos e usando, para isso, a Adição ou Multiplicação, para calcular os valores, em reais. Também, deveria escrever, em "Resultado", o valor total de todos os produtos listados, após efetuar a soma dos valores do total de cada produto. O problema é fechado, uma vez que estão definidos os valores unitários dos produtos e as quantidades de cada, nas imagens, e podem ser aplicados um ou mais algoritmos na resolução (SOUZA; SANTOS, 2007).

Em cada linha, a aluna foi indagada sobre o que havia entendido e orientada a contar os produtos, observando os tipos. Nas duas primeiras, 
tomou a decisão de realizar os cálculos de Adição, para obter os valores totais, em reais, dos produtos.

A partir desse momento, foi questionada se poderia realizar os cálculos de Multiplicação para determinar o valor, quando existe uma quantidade maior de produtos, e ela concordou e optou por executá-los, a fim de verificar se os resultados seriam os mesmos. Entretanto, como não dominava a tabuada, precisou de auxílio para que identificasse que o fator das multiplicações era igual ao número de produtos.

Entre os erros, destaca-se o produto "Bolsa", pois acreditou que na Loja tinham três bolsas para a venda e fez o cálculo na folha, que resultou no valor de $R \$ 120,00$. Ao digitá-lo, apareceu a palavra "Errado!" e quis verificar onde se deu o erro e, por meio de questionamentos, notou que havia contado, também, a bolsa de uma cliente, que havia nas imagens. Então, refez a contagem e o cálculo de Multiplicação, obtendo o valor correto.

Também, no produto "Tênis", como a quantidade era 12, e de "Sapato", seria 14, teve dificuldades em realizar as Multiplicações, porque apresentavam fatores com dois algarismos. Para resolvê-las, precisou que a pesquisadora e professora a ajudasse, já que não dominava tal conhecimento. Da mesma forma, ocorreu ao tentar encontrar o valor do "Resultado", visto que decidiu fazer a soma na folha e não conseguiu fazer a Adição com transporte.

No que se refere a Situação 4, cuja intencionalidade era que fosse respondido o questionamento "O que você compraria?", ao preencher a Tabela, com os nomes dos produtos que escolheria na Situação 3, na coluna "Produto", e o valor, em reais, que seria gasto com cada um, na coluna "Total(R\$)", observando os valores unitários apresentados no problema anterior. Ademais, deveria escrever o valor total a ser gasto na lacuna "Resultado" e o valor que sobraria no "Troco". Como faria as suas próprias escolhas, o problema é do tipo aberto, uma vez que, na resolução, poderia realizar a Adição ou Multiplicação e Subtração de Números Naturais e elaborar as suas próprias estratégias (SOUZA; SANTOS, 2007). 
No processo de resolução, a aluna tomou decisões, após receber as devidas explicações. Ela escolheu três produtos e uma unidade de cada, que, segundo a sua justificativa, era suficiente e facilitaria os cálculos (uma estratégia de resolução). Na cópia do primeiro valor referente à "Blusa" para a Tabela, esqueceu o algarismo zero, mas, nos demais registros, feitos na mesma, escreveu corretamente.

Para calcular o valor do "Resultado", decidiu que faria uma Multiplicação, o que necessitou ser indagada, para que identificasse que deveria adicionar os valores, em reais, dos produtos. Ela apresentou dificuldades em realizá-la, ao ter que fazer o transporte do valor que excedeu para a casa das dezenas. Após a ajuda da pesquisadora e professora, fez a contagem registrando-a na folha, por meio de risquinhos, e, posteriormente, digitou o valor na lacuna respectiva e obteve o êxito na solução.

A determinação do valor de que dispunha foi realizada mentalmente e corretamente, depois que visualizou as imagens das cédulas de dinheiro no enunciado. Por outro lado, não ocorreu da mesma forma para o valor que sobraria, ou seja, o "Troco", pois necessitou fazer o cálculo na folha. Nesse momento, não conseguiu realizar a Subtração com retorno, porque não dominava tal conhecimento, precisando, assim, ser ensinada.

O registro da resolução desse problema encontra-se na Figura 4.

FIGURA 4 - Registros da aluna ao resolver a Situação 4
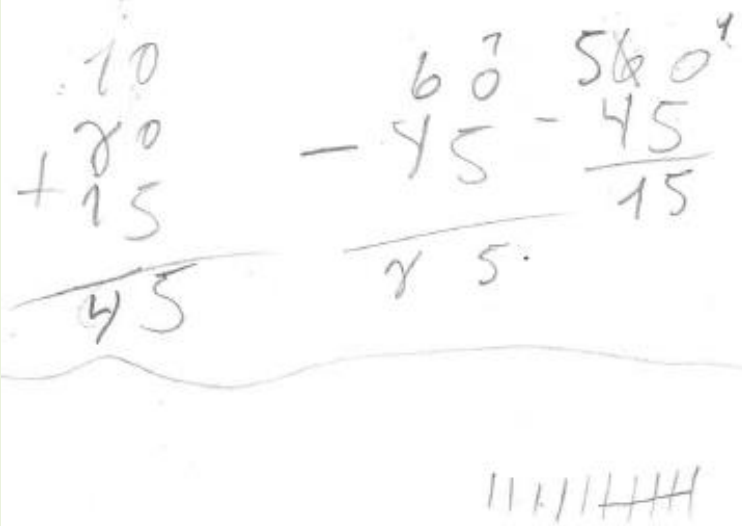

Fonte: a pesquisa. 
No registro da solução do problema, o uso das teclas do computador e o preenchimento da Tabela foram feitos pela aluna, sem o auxílio da pesquisadora e professora. De acordo com o seu depoimento, essa foi uma tarefa fácil, já que o computador facilita a escrita e era uma tarefa diferenciada.

No geral, em todos os problemas, quando o feedback era a palavra "Certo!", para as soluções digitadas, a aluna demonstrou uma grande satisfação. Aqui, vale destacar que, a experiência foi inédita para ela, no que se refere a resolução de problemas com o uso das tecnologias digitais e por ter conseguido encontrar todas as soluções, mesmo precisando ser orientada e ensinada.

Com a realização desta investigação, compreende-se que outros resultados poderiam ser obtidos, caso a aluna tivesse sido auxiliada por outro(s) colega(s), da mesma turma do $6^{\circ}$ ano, ou, até mesmo, pela professora da Sala de Recursos Multifuncionais. Todavia, com o auxílio da pesquisadora e sua professora de Matemática, pôde se expressar de forma mais livre, organizar os processos mentais e fazer os registros escritos das resoluções, segundo o seu ritmo e com um maior tempo disponível, do costumava ser previsto em sala de aula. Também, teve a oportunidade de aprender conhecimentos e minimizar as suas dificuldades na interpretação de enunciados, realização de processos de resolução de cálculos e problemas e apresentação de soluções.

Os problemas abordaram temas que tornaram a resolução com o uso das tecnologias digitais uma atividade motivadora e significativa para a aluna (MIRANDA; PINHEIRO, 2016). Além disso, contribuíram para que desenvolvesse as competências e habilidades de tentar, tomar decisões, refletir, criar, elaborar estratégias, testar, comunicar ideias, entre outras (FIGUEIREDO, 2017, 2019; PAIS, 2013; SOUZA; SANTOS, 2007). Contudo, proporcionaram a exploração, simulação, visualização, experimentação, produção escrita e comunicação, com e sem o uso das tecnologias digitais (FIGUEIREDO, 2017, 2019). 


\section{Considerações finais}

As atividades propostas no ensino da Matemática podem favorecer a inserção dos alunos com deficiência intelectual nas Instituições de ensino regular e prepará-los para a vida cotidiana, em sociedade, desde que o professor de Matemática esteja em constante observação e avaliação do desempenho desses alunos, visto que tais informações podem permitir um planejamento pedagógico consoante com os seus anseios $e$ particularidades, os conteúdos a serem trabalhados e as competências e habilidades desenvolvidas. Desse modo, as práticas pedagógicas inclusivas, na disciplina, devem ter ações processuais e formativas, que utilizem perspectivas metodológicas e recursos adequados, que possam proporcionar a aprendizagem e o desenvolvimento de tais alunos (BRASIL, 2018; RIO GRANDE DO SUL, 2018).

Embora que a investigação tenha apresentado os resultados de um processo formativo, que envolveu apenas uma aluna com deficiência intelectual, foi possivel depreender que, o Design e a resolução de problemas com o uso de tecnologias digitais, é uma perspectiva metodológica capaz de aliar o uso das tecnologias digitais e a abordagem de temas de relevância social, com a intencionalidade de promover o processo de ensino e aprendizagem da Matemática (FIGUEIREDO, 2017, 2019). Quando o Design é realizado pelo professor, em etapas (análise da necessidade, projeto, desenvolvimento e implementação, e avaliação) (FILATRO, 2008), esse escolhe os recursos e cria as possibilidades que possam gerar um ambiente propício para a resolução de problemas contextualizados, fechados ou abertos, com o uso de tecnologias digitais. A resolução desses problemas pode propiciar a realização de processos diferenciados, em que $\mathrm{o}$ aluno com deficiência intelectual tem a oportunidade de se expressar, em linguagem escrita, oral e matemática, explorar e experimentar o uso desses recursos, valorizar os seus interesses e atender as suas necessidades pessoais e educacionais.

Ademais, na resolução desses problemas, o aluno com deficiência intelectual pode organizar os seus processos mentais e ter um maior tempo 
para resolvê-los. Com isso, pode expor suas ideias e aprender conhecimentos matemáticos, a partir de seus conhecimentos prévios e das orientações e questionamentos do professor, no que se refere à Contagem, Representação no Sistema Decimal e de Valores Monetários, execução de cálculos, que sejam articulados ao ensino do uso de recursos tecnológicos e à compreensão de situações problemáticas, que tratam de temas socias.

\section{Referências}

ALLEVATO, N. S. G. O Computador e a Aprendizagem Matemática: reflexões sob a perspectiva da Resolução de Problemas. Disponível em: <http://www.educadores.diaadia.pr.gov.br/arquivos/File/setembro2012/mat ematica_artigos/artigo_alevato.pdf>. Acesso em: 14 de set. 2019.

BRASIL. Constituição da República Federativa do Brasil, 1988. Brasília: Senado Federal, Centro Gráfico, 1988.

. Lei $n^{\circ}$ 13.146, de 6 de julho de 2015. Lei Brasileira de Inclusão da Pessoa com Deficiência (Estatuto da Pessoa com Deficiência). Diário Oficial da União, Brasília, 2015.

. Ministério da Educação. Base Nacional Comum Curricular:

Educação é a base. Educação Básica. Brasília: MEC, 2018. Secretária de Educação Especial. Diretrizes nacionais para a educação especial na educação básica. São Paulo: MEC-SEESP, 2001.

. Senado Federal. Lei de Diretrizes e Bases da Educação Nacional, 1996. Brasília: Coordenação de Edições Técnicas, 2017.

DEPOSITPHOTOS.COM. Imagens utilizadas nos enunciados dos problemas. Disponível em: <www.depositphotos.com>. Acesso em: 14 de set. 2019.

ESPANHA. Organização das Nações Unidas (ONU). A Declaração de Salamanca: Sobre Princípios, Políticas e Práticas na Área das Necessidades Educativas Especiais. Salamanca: ONU, 1994.

ESTEBAN, M. P. S. Pesquisa qualitativa em educação: fundamentos e tradições. Porto Alegre: AMGH, 2010.

FIGUEIREDO, F. F. Design de problemas com a utilização das Tecnologias Digitais na formação inicial de professores de Matemática (Tese de Doutorado). Universidade Luterana do Brasil, Canoas, Brasil, 2017. 
. Designs de enunciados para la (re)formulación y resolución de problemas con la utilización de tecnologías digitales en la formación inicial de profesores de Matemática. Revista Paradigma, v.40, n.extra. 1, pp.126149, junio, 2019.

FILATRO, A. C. Design instrucional na prática. São Paulo: Pearson Education do Brasil, 2008.

GOMES, A. L. L. et al. Atendimento Educacional Especializado em Deficiência Mental. Brasília: SEESP/SEED/MEC, 2007.

KE, X.; LIU, J. Deficiência Intelectual. In: REY, J. M. (Org.). IACAPAP e-Textbook of Child and Adolescent Mental Health. Disponível em:

<https://iacapap.org/content/uploads/C.1-Intelectual-disabilities-PORTUGUES E-2015.pdf>. Acesso: 7 jan. 2020.

MIRANDA, A. D. de; PINHEIRO, N. A. M. O ensino da Matemática ao deficiente intelectual: projetos de trabalho em uma perspectiva contextualizada e interdisciplinar. Revista Educação Especial, v.29, n.56, p.695-708, set.-dez., 2016.

RIO GRANDE DO SUL. Secretaria de Estado da Educação. Referencial Curricular Gaúcho: Matemática. Porto Alegre: Secretaria de Estado da Educação, Departamento Pedagógico, 2018.

PAIS, L. C. Ensinar e aprender Matemática. 2.ed. Belo Horizonte: Autêntica, 2013.

SCHALOCK, R. L. et al. A Holistic Theoretical Approach to Intellectual Disability: Going Beyond the Four Current Perspectives. Intellect Dev Disabil, v.56, n.2, pp.79-89, apr., 2018.

SEIBERT, T. E.; GROENWALD, C. L. O. Contribuições da neurociência para a educação matemática de uma pessoa com necessidades educativas especiais intelectivas. Revista Educação Especial, v.27, n.48, p.233-248, jan.abr., 2014.

SOUZA, L. P. de; SANTOS, S. A. dos. Problemas matemáticos abertos e o predomínio da calculadora. In: ENCONTRO NACIONAL DE PESQUISA EM EDUCAÇÃO EM CIÊNCIAS, 7., 2007, Florianópolis. Anais eletrônicos...

Florianópolis: ENPEC-UFSC, 2007. Disponível em:

<http://www.fep.if.usp.br/ profis/arquivos/vienpec/CR2/p661.pdf>. Acesso em: 15 nov. 2019.

USA. American Association on Intellectual and Developmental Disabilities. USA: AAIDD, 2019. Disponível em: <https://www.aaidd.org/intellectualdisability/definition>. Acesso: 20 dez. 2019. 
Recebido em: 03 de maio de 2020 Aprovado em: 12 de setembro de 2020 Publicado em: 28 de setembro de 2020

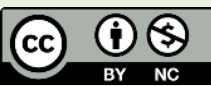

